Upaya Peningkatan Mutu...(Mulyadi et al.)

\title{
MODEL PENJAMINAN MUTU KETERCAPAIAN KOMPETENSI DASAR DALAM SISTEM PEMBELAJARAN ONLINE PADA SITUASI WORK FROM HOME (WFH)
}

\author{
Dwi Astuti, Eko Supriyanto, Muthoifin \\ Magister Pendidikan Agama Islam Universitas Muhammadiyah Surakarta \\ E-Mail: dwiastuti2703@gmail.com,es113@ums.ac.id,mut122@ums.ac.id
}

\begin{abstract}
Abstrak: Tujuan penelitian ini untuk mengembangkan model penjaminan mutu terhadap ketercapaian KD untuk mata pelajaran Pendidikan Agama di tengah wabah Covid19 di satuan pendidikan Sekolah Dasar. Situasi yang tidak normal dalam tatanan pembelajaran karena Covid 19 menuntut pembelajaran untuk mencapai standar kompetensi dasar harus tetap dilakukan, sehingga diperlukan pelaksanaan pembelajaran yang terjamin mutunya dan memenuhi standar kompetensi. Karakteristik mata pelajaran Pendidikan agama yang berdomain utama afektif dan kognitif membutuhkan model penjaminan mutu pembelajaran yang khusus serta disesuaikan dengan karakter siswa di daerah pedesaan dan tingkat Sekolah Dasar (KD). Untuk mencapai tujuan tersebut jenis riset yang ditempuh adalah $R \mathcal{E} D$ dengan disertai metode pengumpulan data yaitu wawancara dan dokumentasi. Analisis data menggunakan teknik analisis mengalir (flow analysis) yang dilengkapi dengan pemodelan yang dikuatkan dengan FGD yang menghadirkan stakeholder. Subyek penelitian dari penelitian ini adalah guru, siswa dan orang tua siswa kelas VI Sekolah Dasar. Sedangkan untuk memperoleh data yang valid dan bisa dipertanggungjawabkan telah ditempuh trianggulasi dengan cara member check agar diperoleh data yang benar benar valid. Model penjaminan mutu ketercapaian KD untuk mata pelajaran pendidikan agama menempuh sistem sajian melalui youtube dan wa group yang diseleksi dalam dua tahapan agar mutu pembelajaran tergaransi. Tiga tahapan tersebut adalah persiapan yang berusaha mengidentifikasi level dan bobot tuntutan dari pernyataan KD serta menemukan standar instrumen standar mutu, kedua pada tahapan dalam pelaksaan pembelajaran berupa seleksi materi pelajaran yang dikontrol dengan bobot KD sehingga materi dalam youtube dikendalikan dengan kriteria harus memiliki dua domain yaitu kognitif dan afektif. Tahapan ketiga yaitu kontrol mutu yang dilakukan dengan pemberian kuis dan tes terkait dengan penguasaan materi sesuai target KD yang ditetapkan. Keseluruhan tahapan selalu dikontrol dengan instrumen standar mutu yang dikeluarkan oleh Kemdikbud khusus Sekolah Dasar. Model penjaminan mutu disesuaikan feasiblitasnya melalui FGD yang diadakan dengan melibatkan stakeholders.
\end{abstract}

Kata kunci: identifikasi level dan bobot bobot;; penjaminan mutu afektif dan kognitif; pembelajaran

\section{PENDAHULUAN}

Hadirnya sekolah bermutu tidak mungkin terjadi tanpa penyediaan strategi perencanaan dan upaya penjaminan mutu (Robert W Ewy. 2009:1) apalagi di dalam situasi belajar yang tidak normal saat terjadinya wabah Covid 19 yang mengubah sistem interaksi interuksional sekolah. Oleh karena itu tuntutan kemunculan penjaminan dalam salah satu komponen pendidikan seperti penjaminan mutu proses pembelajaran atau kurikulum menjadi keniscayaan untuk setiap sekolah disaat covid 19 menjadi perhatian serius. Dalam tinjauan lain pada sisi sekolah, penjaminan mutu 
pendidikan difungsikan sebagai bentuk pemenuhan tuntutan standar yang diharapkan oleh stakeholders yang telah ditetapkan sebagai akuntabilitas sekolah terhadap masyarakat. (Reichenbächer\& Einax,2011).

Tantangan baru dalam format penjaminan mutu saat covid 19 menjadi tuntutan yang tidak terelakkan karena ternyata masa siswa tidak bisa belajar telah berlangsung lama yang dikawatirkan secara signifikan akan mengancam mutu sekolah dalam pencapaian kompetensi dasar yang sudah dipatok sebelumnya. Keprihatinan model kelulusan yang berlangsung tanpa adanya ujian nasional dan ujian sekolah turut mengkondisikan mutu pendidikan yang saat ini terjadi. Hadirnya penjaminan mutu dalam pembelajaran yang kontektual dengan model pembelajaran yang berkarakter distance learning ini sangat dibutuhkan baik untuk sekolah baik didaerah pendesaan maupun perkotaan.

Pemberlakuan pemenuhan standar pada penyelenggaraan pendidikan sudah menjadi kewajiban imperatif bagi sekolah di Indonesia sesuai dengan regulasi yang berlaku sejak tahun 1990 melalui ketentuan penetapan standar minimal pendidikan untuk menjamin keberlanjutan dan masyarakat sekolah mendapat perlindungan selaku stakeholders. Penetapan standar layanan pendidikan melalui penetapan kualitas dengan penjaminan mutu akan mengarahkan padapenyelenggaraanyang menjamin ketercapaian secara rasional target pendidikan yang ditetapkan. Tuntutan ini terlebih ketika mulai adanya penciutan anggaran pendidikan akibat situasi ekonomi nasional sehingga sangat diperlukan adanya langkah efisiensi dari perspektif value for money mapun tuntutan akuntabilitas sekolah. (Alves $\mathrm{H}$ and Raposo M. 2007: 796.) Kedudukan penjaminan mutu ditempatkan sebagai layanan kualitas untuk bisa mencapai standar yang ditetapkan bahkan upaya penjaminan dan peningkatan mutu pendidikan dijalankan dan diarahkan semaksimal mungkin agar sekolah dapat memberikan layanan yang sesuai dengan atau melebihi standar nasional pendidikan (Moerdiyanto, 2009).

Keberhasilan layanan penjaminan mutu ini tidak terlepas dari kemampuan guru dalam memfasilitasi dan mengembangkan proses pembelajaran. Keberhasilan proses pembelajaran dapat dilihat melalui penilaian maupun kemunculan kesadaran budaya mutu (Edward Sallis.2002). Penilaian menurut (Daji, Mulyasa \& Warta, 2019) adalah kegiatan yang dilakukan guru untuk mengukur penguasaan dan ketercapaian Kompetensi Dasar peserta didik. Berdasarkan Permendikbud No.24 Th 2016 tentang Kompetensi Inti dan Kompetensi Dasar, Pasal 2 ayat 2 menyatakan bahwa Kompetensi Dasar merupakan kemampuan dan materi pebelajaran minimal yang harus dicapai peserta didik untuk suatu mata pelajaran pada masing-masing satuan pendidikan yang mengacu pada Kompetensi Inti (Kemendikbud, 2016)

Wabah Coronavirus Disease (Covid -19) yang terjadi di lebih dari 118 negara di dunia telah ditetapkan oleh organisasi kesehatan dunia World Health Organization (WHO) sebagai pandemic (Sohrabi, et al. 2020) mengharuskan sistem sekolah memodifikasi delevery system dalam pembelajarannya. Dengan belum ditemukannya vaksin, maka banyak negara telah menerapkan berbagai macam langkah untuk memperlambat penyebaran virus ini, dengan isolasi, karantina dan soacial distancing (Smith \& Freedman, 2020). Kondisi ini ada prediksi pemulihan sistem persekolah menjadi lebih lama dan berpotensi untuk menurunkan mutu pendidikan bagi anak bangsa. Isolasi yaitu pemisahan pasien dengan penyakit menular dari 
orang yang tidak terinfeksi untuk melindungi orang yang tidak terinfeksi dan biasanya dilakukan di rumah sakit. (Smith \& Freedman, 2020). Karantina yaitu pembatasan gerak orang yang diduga telah terkena penyakit menular tetapi tidak sakit, baik karena mereka tidak terinfeksi atau karena mereka masih dalam masa inkubasi (Smith \& Freedman, 2020). Pembatasan jarak sosial atau yang lebih akrab disebut social distancing bertujuan untuk membuat orang terpisah satu sama lain dengan meminta mereka tinggal dirumah untuk mengurangi kontak langsung. Social distancing mengkondisikan format interaksi instruksional menjadi berbentuk lain dari masa normal. Dampak dari pembatasan jarak sosial ini terlihat jelas dampaknya di China yang lebih awal menerapkannya dibanding dengan Italia yang lebih lambat dalam menerapkan kebijakan ini (Greenstone \& Nigam, 2020).

Pandemi

Covid-19

telah

mempengaruhi sistem pendidikan di seluruh dunia, yang mengarah ke penutupan sekolah, perguruan tinggi dan universitas yang tersebar luas. Menurut data dari UNESCO, pada 26 April 2020, sekitar 1.579.599.850 peserta didik telah terpengaruh karena penutupan sekolah sebagai respons terhadap pandemi, 189 negara telah menerapkan penutupan nasional dan telah menerapkan penutupan lokal, berdampak pada 90,2 \% peserta didik dunia (UNESCO, 2020). Indonesia sebagai negara yang juga terkena pandemi ini menunjukan ketidaksiapan untuk mencari solusi kebuntuan sistem intruksional di masa pandemi sehingga sekolah di pedesaan banyak mengalami stagnan bahkan tidak berlangsung sama sakali pembelajaran. Memang di beberapa sekolah di SD tertentu dicari jalan keluar melalui guru kunjung dengan siswa terbatas tetapi ada juga yang menerapkan model online walaupun dengan pelaksanaan sederhana.

Dipastikan dengan kondisi hal tersebut akan berpengaruh pada kualitas ketercapaian kurikulum atau KD yang tidak bisa disajikan saat pembelajaran yang diliburkan. Oleh karena itu diperlukan munculnya model baru penjaminan mutu untuk ketercapaian KD di saat wabah Covid 19. Diperlukan mekanisme penjaminan mutu yang memberikan garansi secara virtual KD dalam diraih oleh siswa.

Indonesia telah menetapkan kebijakan Work From Home (WFH) yang berarti bekerja dari rumah sebagai langkah antisipasi terutama untuk siswa yang harus sekolah. Hal ini ditempuh agar proses belajar tetap berjalan walaupun dari sisi kuantita kurang memenuhi. Sekolah memilih untuk meniadakan kelas dan mengubah Kegiatan Belajar Mengajar (KBM) menjadi pembelajaran online untuk mencapai KD tertentu yang telah ditargetkan (Kemendikbud, 2020). Pembelajaran online menurut Anderson (2008) didefinisikan sebagai penggunaan jaringan Internet untuk mengakses materi pembelajaran; untuk berinteraksi dengan konten, instruktur, dan pelajar lain; dan untuk mendapatkan, mendukung selama proses pembelajaran, untuk memperoleh pengetahuan, untuk membangun makna pribadi, dan untuk tumbuh dari pengalaman belajar. Secara konsep memang telah disolusikan dengan online namun ternyata di lapangan terdapat berbagai kendala antara lain sulitnya akses jaringan maupun tidak semua daerah tersedia saluran internet yang dimanfaatkan untuk belajar online. Karena itu muncul pertanyaan: bagaimana mutu penyerapan materi yang dikemas dalam KD dapat dikuasai oleh siswa serta modelnya seperti apa yang memungkinkan masih diselenggarakan oleh sekolah dalam keterbatasan tersebut.

Pergeseran proses pendidikan dari pembelajaran kelas tradisional menjadi 
pembelajaran berbasis komputer (online) mungkin menjadi eksperimen pendidikan terbesar abad ini. Oleh karenanya sangat penting mengetahui apakah hal tersebut membantu peserta didik dalam mencapai atau mendapat pengetahuan yang harusnya mereka dapatkan di sekolah (Lall \& Singh, 2020) Kebijakan pembelajaran secara online tidak hanya mempengaruhi minat peserta didik dalam belajar, tetapi juga mepengaruhi kompetensi para pendidik dalam meggunakan metode dan media pembelajaran (Rusdiana,et al. 2020). Teknologi yang digunakan di era pandemi akan mengubah perilaku dan budaya baru pada pasca pandemi (Praherdhiono,et al. 2020). Oleh karena itu, dilakukan penelitian ini dengan tujuan untuk mendiskripsikan model penjaminan mutu ketercapaian Kompetensi Dasar (KD) dalam sistem pembelajaran online pada situasi Work From Home (WFH).

\section{METODE PENELITIAN}

Tujuan penelitian ini untuk mendapatkan formulasi model penjaminan mutu untuk pencapaian KD disaat pembelajaran tidak bisa dilakukan secara normal karena terjadinya distance learning sehingga terjadi pembelajaran melalui virtual. Diambil mata pelajaran pendidikan agama karena pelajaran ini memiliki karakterristik berdomain kognitif, dan afektif, sehingga diperlukan pembelajaran virtual yang mampu mengantarkan muatan konten yang berdomain yang dituntut.

Penelitian ini merupakan penelitian riset dan pengembangan (R\&D) karena kajian artikel ini bertujuan untuk merancang model penjaminan mutu pada mata pelajaran yang berdemensi ganda yaitu kognitif dan afektif di saat sedang terlanda wabah covid 19. yang berkarakter pembelajaran daring. Selain itu juga penelitian riset dan pengembangan ini bertujuan untuk memperoleh data secara obyektif dan alamiah yang mendasari penyusunan model penjaminan mutu pembelajaran di saat pandemi covid 19 (Sugiyono.2018).

Teknik pengumpulan data dilakukan dengan menggunakan metode wawancara untuk mengetahui model penjaminan mutu yang sudah ditempuh oleh guru, metode dokumentasi untuk memperoleh data terkait dengan data dokumen bahan ajar yang di onlinekan serta data yang terkait dengan indikator penjaminan mutu untuk khusus Sekolah Dasar. Sedangkan untuk menemukan data secara autentik serta dapat digunakan sebagai data pendukung analisis menuju simpulan yang valid maka digunakan triangulasi member check yaitu mencari sebanyak mungkin anggota subyek penelitian untuk mendapatkan data yang paling benar dan mayoritas membenarkannya.

Sumber data yang dijadikan sebagai subyek penelitian adalah guru pengampu mata pelajaran agama, siswa kelas VI yang sedang menempuh mata pelajaran agama serta orang tua siswa. Penggunaan subyek penelitian bersifat meluas artinya memungkinkan jumlah subyek penelitian yang dijadikan sebagai sumber data bisa bertambah dari perencanaan awal sehingga kuantita subyek penelitian sebagai sumber data menganut snow balling. Prinsip ini ditempuh karena agar supaya penelitian memiliki varian sumber data yang dapat menjawab tujuan penelitian. (Muthoifin, 2015) Untuk melakukan analisis data yang sudah masuk dikenakan analisis mengalir (flow analysis) dari Miles dan Huberman (1992).

Pemilihan analisis ini karena agar dimungkinkan peneliti untuk melakukan pengambilandatakembaliketikasimpulan yang diperoleh belum memenuhi tuntutan peneliti untuk menghasilkan simpulan yang dikehendaki. Analisis data dilakukan dengan tahapan melalui : pengumpulan data, reduksi data, penyajian data dan penarikan 
kesimpulan atau verifikasi. Data yang telah dikumpulkan, kemudian dilakukan reduksi data dengan merangkum, menyederhanakan dan memilih data yang dibutuhkan yang dipandu dengan pertanyaan penelitian. Setelah data direduksi dan digolongkan, kemudian disajikan dan diverifikasi dengan berbagai fakta dilapangan dan terakhir adalah diambil kesimpulan yang menunjukkan bentuk model penjaminan mutu yang dimaksud. Untuk mempertajam hasil model yang ditemukan agar lebih layak maka ditempuh langkah FGD untuk memperoleh tingkat kelayakan implementasidilapangan.Sebagailangkah hati-hati maka dikembangkan langkah komparasi dengan instrumen penjaminan mutu yang telah dikembangkan oleh Kementrian Pendidikan dan Kebudayaan. FGD menghadirkan berbagai pihak yang dimasukkan sebagai stakeholers. Yaitu guru, siswa dan orang tua.

\section{HASIL DAN PEMBAHASAN}

Penelitian ini berlokasi di SD $\mathrm{N}$ Karanganom I dengan mengambil subyek penelitian berupa siswa kelas VI semester genap 2020. Pelaksanaan penelitian berlangsung pada bulan Maret sampai Mei 2020 dengan memilih pada mata pelajaran Pendidikan Agama Islam selama diberlakukannya kebijakan Work From Home di Indonesia. Setiap pertemuan dilakukan dengan alokasi waktu 35 menit. Pembelajaran secara online yang digunakan menggunakan media WhatsApp dan Youtube. Pemilihan lokasi penelitian di SD tersebut karena sekolah tersebut siswanya siap untuk melaksanakan pembelajaran secara online dan pilihan youtube karena lebih menarik serta memiliki varian content yang banyak sehingga bisa disesuakan dengan KD mata pelajaran Agama. (Meti, 2017)

Awalnya, guru membuat satu grup WhatsApp yang berisi seluruh peserta didik kemudian memberikan materi di grup tersebut dengan memberi link video yang ada di Youtube sehingga peserta didik lebih paham. Melalui youtube yng sudah ditunjukan melalui alamat link nya maka siswa dapat mengekplotrasi isi mata pelajaran secara longgar waktu. Pemilihan youtube untuk content mata pelajaran Agama karena memungkinkan melalui youtube bisa disajikan pesan materi secara kognitif maupun afeektif yang itu dituntut harus ada dalam mata pelajaran Agama. Youtube yang mengandung unsur kognitif, afektif bahkan skill dapat dijadikan jaminan untuk mendukung ketercapaian KD pendidikan agama sebab sesuai dengan karakter mata pelajaran agama yang afektif. (Haeroni, 2016)

Setelah melakukan pembelajaran online melalui Whats App, guru melakukan evaluasi terkait Kompetensi Dasar (KD) yang telah dicapai peserta didik. Evaluasi untuk pembelajaran online dalam mencakup penilaian peserta didik dan evaluasi pengajaran. Penilaian peserta didik dilakukan dengan tes tulis dan tes praktik, sedangkan untuk sikap diperoleh dari interaksi dan partisipasi selama pembelajaran di group WhatsApp. Evaluasi pembelajaran dilakukan guru dengan merefleksikan kegiatan pembelajaran yang telah dilakukan.

Dampak yang dirasakan peserta didik dalam pembelajaran online ini diantaranya adalah mereka dipaksa untuk belajar jarak jauh ditengah fasilitas dan sarana yang kurang memadai, misalnya koneksi internet yang buruk atau handphone digunakan bersama orangtua, selain itu peserta didik belum terbiasa dengan pembelajaran jarak jauh yang biasanya bertatap muka harus beradaptasi dengan metode baru yang digunakan guru, peserta didik juga merasakan jenuh dan bosan akibat tidak pergi ke sekolah dan mereka tidak dapat berinteraksi langsung dengan temanteman dan gurunya. 
Wawancara dengan guru menyatakan bahwa ada beberapa kendala dalam pembelajaran online ini, diantaranya: tidak semua anak hadir dalam pembelajaran karena keterbatasan kuota atau jaringan yang kurang mendukung. Peserta didik terkadang merasa bosan, materi yang disampaikan tidak sepenuhnya dapat diapahami. Menurut (Purwanto et. al. 2020) beberapa hal yang dapat dilaksanakan agar menciptakan pengalaman belajar yang menarik dalam pembelajaran online adalah: menciptakan dan memelihara lingkungan belajar yang positif; membangun komunitas belajar; memberikan umpan balik yang konsisten secara tepat waktu; dan menggunakan teknologi yang tepat untuk mengirimkan konten yang tepat.

Teknologi yang paling diminati dalam pembelajaran online adalah media sosial, kemudian web. Karena keduanya relatif mudah dalam penggunaannya. Temuan beberapa peneliti yang dilakukan bahwa media sosial adalah salah satu sarana peserta didik saling berbagi pengetahuan. Penelitian yang dilakukan Gon \& Rawekar (2017) menjelaskan bahwa Whatsapp dapat mendukung pembelajaran karena dapat mengkombinasikan antara teks, gambar, video maupun catatan suara. Selain itu, peserta didik juga memperoleh pengalaman belajar yang baru, dapat lebih berekspresi dalam diskusi, suasana belajar (chat) sangat santai, belajar menjadi lebih update, serta dapat diakses dimana saja jika peserta didik lupa materi yang telah dipelajarinya. (Pratama. 2019)

Peran guru tidak dapat dipisahkan dengan kegiatan pembelajaran di era pandemi ini, dengan menganut prinsip social distancing dan physycal distancing, maka kegaiatan belajar mengajar tidak bisa dilakukan secara tatap muka, melainkan dengan pembelajaran online. Guru harus memiliki beberapa kemampuan agar mampu melaksanakan pembelajaran dengan baik dan efktif di masa pandemi ini yaitu kemampuan pengajaran yang meliputi : teknologi, pedagogi dan konten pembelajaran. (Muthoifin, 2015) (Praherdhiono, et al. 2020).

Dalam hal pedagogi, kemandirian belajar merupakan pendekatan yang diterapkan hampir menyeluruh di sekolah, terutama Sekolah Dasar. Selain itu, Komunikasi antara peserta didik dan guru merupakan hal yang harus diperhatikan dalam pembelajaran online sehingga standar kompetensi yang diharapkan dapat terpenuhi (Latchem, 2014)

Beberapa hal yang diperhatikan dalam pembelajaran Online saat pandemi Covid-19 ini menurut Verawardina (2020) adalah : 1) mempersiapkan fasilitas dan materi pembelajaran yang akan digunakan dalam pembelajaran online 2) mempersiapkan model, metode, teknik dan strategi yang akan digunakan 3) Membuat instruksi pembelajaran menjadi jelas, terutama mengenai jadwal pembelajaran online mereka, menjelaskan ruang lingkup pembelajaran seperti standar kompetensi, kompetensi dasar, tujuan dan pencapaian 4) Sistem evaluasi dalam pembelajaran online misalnya dengan ketersediaan bank soal yang dapat digunakan oleh guru untuk mengevaluasi peserta didik.

Penjaminan mutu merupakan salah satutujuanditetapkannyastandarnasional pendidikan. Standar nasional pendidikan meliputi standar isi, standar proses, standar kompetensi lulusan, standar tenaga kependidikan, standar sarana dan prasarana, standar pengelolaan, standar pembiayaan dan standar penilaian pedidikan. Komponen tersebut diharapkan mampu meningkatkan atau minimal menjadikan mutu pendidikan di suatu sekolah berada pada taraf yang baik dan layak mengacu pada kelayakan yang ditentukan pemerintah.

Program pembelajaran online harus dirancang untuk memastikan kesempatan 
belajar peserta didik yang adil dan masuk akal untuk behasil menyelesaikan dan mencapai standar kompetensi yang diperlukan. Sekolah juga harus memastikan bahwa isi semua materi pembelajaran tetap terkini dan relevan, strategi pengajaran, dan bentuk penilaian telah disesuaikan dengan Kompetensi Dasar.

Penjaminan mutu ketercapaian KD dalam sistem pembelajaran online pada situasi Work From Home (WFH) adalah upaya maksimal yang bisa dilaksanakan oleh satuan pendidikan dalam hal ini sekolah yang dilakukan untuk mempertahankan dan meningkatkan mutu pembelajaran yang langkahlangkahnya meliputi perencanaan, pelaksanaan dan evaluasi yang memenuhi tabel diatas.

Karena tuntutan akuntabilitas publik meningkat untuk pendidikan di sekolah, institusi harus menunjukkan kualitas dalam program dan proses, termasuk yang disediakan melalui pendidikan online (Shelton, 2012). Penilaian pendidikan sebagai proses pengumpulan dan pengolahan informasi yang didapat dari berbagai proses dan kegiatan untuk mengukur pencapaian hasil belajar peserta didik selama dilaksanakannya pembelajaran online yang mencakup: ulangan, penilaian diri, penilaian portofolio maupun unjuk kinerja. Penilaian yang dilakukan guru juga harus memenuhi prinsip-prinsip penilaian, diantaranya; terpadu, obyektif, transparan, edukatif, akuntabel, dan ekonomis (Sani et.al. 2015)

Kompetensi Dasar (KD) merupakan kompetensi yang dipelajari peserta didik untuk suatu mata pelajaran di kelas tertentu. Penguasaan kompetensi ranah sikap, kognitif, psikomotorik, dan pengetahuan untuk suatu satuan pendidikan dan mata pelajaran ditandai oleh banyaknya KD suatu mata pelajaran. Untuk menilai penguasaan kompetensi sesuai dengan tuntutan dalam Standar Kompetensi (SK) dan Kompetensi Dasar (KD), maka guru harus melakukan evaluasi dengan berbagai cara (Salamah, 2018).

Guru memantau setiap proses, kemajuan, kelebihan, kekurangan serta memperbaiki hasil belajar peserta didik dengan evaluasi hasil belajar yang dilakukan secara berkesinambungan. Pemilihan metode yang tepat dalam penilaian akan berpengaruh dalam validitas dan objektivitas hasil penilaian yang berpengaruh pada kualitas pendidikan. Penilaian pada pembelajaran online selama situasi WFH dilakukan dalam berbagai teknik untuk semua kompetensi dasar yang dikategorikan dalam tiga aspek, yaitu sikap, pengetahuan, dan keterampilan yang menurut Sani et.al (2015) dijabarkan sebagai berikut:

Penilaian aspek sikap dilakukan melalui observasi saat pembelajaran, penilaian diri, penilaian antarteman serta jurnal selama proses pembelajaran berlangsung.

a. Observasi

Adalah teknik penilaian yang dilakukan menggunakan format observasi yang telah dibuat sebelumnya dan menggunakan indera baik secara langsung maupun tidak langsung. Dalam pembelajaran online, dapat dilakukan dengan mengamati keaktifan siswa ketika diskusi saat pembelajaran

b. Penilaian antar teman

Adalah teknik penilaian dengan cara meminta peserta didik untuk saling menilai satu sama lain. Instrumen yang digunakna berupa lembar penilaian antar peserta didik.

c. Penilaian diri

Adalah teknik penilaian dengan cara meminta peserta didik untuk merefleksikan kelebihan dan kekurangan diri sendiri dalam 
konteks pencapaian kompetensi. Instrumen yang digunakan berupa lembar refleksi peserta didik.

d. Jurnal guru

Adalah catatan kesinambungan hasil dari observasi yang dilakukan oleh guru.

Penilaian aspek pengetahuan dilakukan dengan Tes tulis, tes lisan, maupun penugasan.

\section{a. Tes tulis}

adalah tes yang soal dan jawabannya tertulis. Dapat berupa pilihan ganda, isian singkat, uraian, benar-salah atau menjodohkan.

b. Tes lisan

adalah tes yang dilakukan guru dengan cara memberikan pertanyaan secara lisan lalu siswa menjawab pertanyaan tersebut dengan lisan juga. Atau bisa berupa tes hafalan secara lisan.

c. Penugasan

adalah penilaian yang dilakukan guru dengan cara memberikan tugas atau pekerjaan rumah baik secara individu maupun kelompok.

Penilaian aspek keterampilan dapat dinilai dengan cara uji kinerja, proyek maupun portofolio.

a. Uji kinerja

adalah penilaian dimana peserta didik melakukan suatu tugas/kinerja yang dapat mengaplikasikan kompetensi dasar yang telah dipelajari. Instrumen yang digunakan berupa check list atau rating scale yang di lengkapi rubrik penilaian.

b. Proyek

adalah penilaian terhadap suatu tugas yang harus diselesaikan pada waktu tertentu. Mulai dari perencanaan hingga pelaksanaan. Instrumen yang digunakan berupa check list atau rating scale yang di lengkapi rubrik penilaian.
Evaluasi dilakukan dalam rangka pengendalian mutu pendidikan secara nasional sebagai bentuk akuntabilitas penyelenggara pendidikan kepada pihak-pihak yang berkepentingan, sesuai yang tercantum dalam UndangUndang Sistem Pendidikan Nasional No. 20 tahun 2003, pada Bab XVI Pada Pasal 57 ayat (1). tentang Evaluasi, Akreditasi dan Sertifikasi. Penilaian pendidikan dikaitkan dengan pengendalian mutu suatu satuan pendidikan dinyatakan dalam UU Sisdiknas No. 20 tahun 2003.

Penilaian yang telah disebutkan dalam Undang-undang dan standar nasional pendidikan diatas, merupakan dasar evaluasi yang dapat digunakan sebagai penjaminan mutu suatu satuan pendidikan selama masa pandemi Covid-19 yang menyebabkan pembelajaran berada pada situasi Work From Home (WFH) sehingga Standar Kompetensi dan Kompetensi Dasar peserta didik dapat terpenuhi.

\section{KESIMPULAN}

Sekolah dapat mempertahankan sekaligus meningkatkan mutu pembelajaran melalui Penjaminan mutu ketercapaian Kompetensi Dasar dalam sistem pembelajaran online pada situasi Work From Home (WFH) sebagai upaya maksimal yang dapat dilakukan oleh institusi pendidikan yang mekanismenya telah dideskripsikan dalam penelitian ini. Model penjaminan mutu ketercapaian KD untuk mata pelajaran pendidikan agama menempuh sistem sajian melalui youtube dan wa group yang diseleksi dalam dua tahapan agar mutu pembelajaran tergaransi. Tiga tahapan tersebut adalah persiapan yang berusaha mengidentifikasi level dan bobot tuntutan dari pernyataan KD serta menemukan standar instrumen standar mutu, kedua pada tahapan dalam pelaksaan pembelajaran berupa seleksi materi pelajaran yang dikontrol dengan bobot KD sehingga materi dalam 
youtube dikendalikan dengan kriteria harus memiliki dua domain yaitu kognitif dan afektif. Tahapan ketiga yaitu kontrol mutu yang dilakukan dengan pemberian kuis dan tes terkait dengan penguasaan materi sesuai target KD yang ditetapkan. Keseluruhan tahapan selalu dikontrol dengan instrumen standar mutu yang dikeluarkan oleh Kemdikbud khusus Sekolah Dasar. Model penjaminan mutu disesuaikan feasiblitasnya melalui FGD yang diadakan dengan melibatkan stakeholders.

\section{DAFTAR PUSTAKA}

Allais, Stephanie Matseleng. (2009). Quality Assurance in Education. Johannesburg: Centre for Education Policy Development.

Alves H and Raposo M. (2007): 796. Student satisfaction index in Portuguese public higher education. Service Indiviual journal

Anderson, T. (Ed.). (2008). The theory and practice of online learning. Athabasca University Press.

Basilaia, G., \& Kvavadze, D. (2020). Transition to Online Education in Schools during a SARS-CoV-2 Coronavirus (COVID-19) Pandemic in Georgia. Pedagogical Research, 5(4).

Britto, M., Ford, C., \& Wise, J. M. (2013). Three institutions, three approaches, one goal: Addressing quality assurance in online learning. Online Learning Journal, 17(4).

Cuttance, Peter. (1998). Quality Assurance Reviews as a Catalyst for School Improvement in Australia. A. Hargreaves et al. ( eds.), International Handbook of Educational Change, 1135-1162. Kluwer Academic Publishers.

Daji, D., Mulyasa, E., \& Warta, W. (2019). Implementasi Sistem Penilaian Kurikulum 2013 di Sekolah Menengah Pertama (SMP). Nusantara Education Review, 1(2), 5764.

Darmalaksana, W., Hambali, R., Masrur, A., \& Muhlas, M. (2020). Analisis Pembelajaran Online Masa WFH Pandemic Covid-19 sebagai Tantangan Pemimpin Digital Abad 21. Karya Tulis Ilmiah (KTI) Masa Work From Home (WFH) Covid-19 UIN Sunan Gunung Djati Bandung, 1-12.

Gon, S., \& Rawekar, A. (2017). Effectivity of e-learning through WhatsApp as a teaching learning tool. MVP Journal of Medical Science, 4(1), 19-25.

Greenstone, M., \& Nigam, V. (2020). Does Social Distancing Matter?. University of Chicago, Becker Friedman Institute for Economics Working Paper, (2020-26).

Haironi, Adi. Implementasi Metode Ta fi ulqur'an "Sabaq, Sabqi, Manzil" Di Marhalah Mutawasithahdan Tsanawiyahputri Pondok Pesantren Imam Bukhari Tahun Pelajaran 2010-2014, Ums 2016

Huber, S. G., \& Gördel, B. (2006). Quality assurance in the German school system. European Educational Research Journal, 5(3-4), 196-209.

Kemendikbud. (2020, March 16). Surat Edaran Nomor 3 Tahun 2020 tentang Pencegahan COVID-19 pada Satuan Pendidikan. https://lldikti12.ristekdikti.go.id/2020/03/12/ surat-edaran-nomor-nomor-3-tahun-2020-tentang-pencegahan-covid-19-padasatuan-pendidikan.html 
PROFETIKA, Jurnal Studi Islam, Vol.21, No. 1, Special Issue 2020: 129-139

Kemendikbud (2016). Peraturan Menteri Pendidikan Dan Kebudayaan Republik Indonesia Nomor 24 Tahun 2016 Tentang Kompetensi Inti Dan Kompetensi Dasar Pelajaran Pada Kurikulum 2013 Pada Pendidikan Dasar Dan Pendidikan Menengah. Kementrian Pendidikan dan Kebudayaan

Lall, S., \& Singh, N.(2020). CoVid-19: Unmasking the new face of Education. International Journal of Research in Pharmaceutical Sciences, 11(SPL1), 48-53.

Latchem, C. (2014). Quality assurance in online distance education. Online distance education: Towards a research agenda, 311.

Moerdiyanto. (2009). Strategi Pelaksanaan Sistem Penjaminan Mutu Pendidikan (SPPMP) Oleh Pemerintah Kabupaten/Kota. Jurnal Informasi, No. 2, XXXV, Th. 2009.

Fatimah, Meti. Metode Hafalan Al Qur'an Siswa Kelas V Sekolah Dasar Islam Terpadu Ibnu Umar Dan Sekolah Dasar Muhammadiyah Program Khusus Boyolali Tahun 2015/2016, 2017

Muthoifin. Pemikiran Pendidikan Multikultural Ki Hadjar Dewantara, dalam Jurnal Intizar, Vol. 21, No. 2: 299. 2015.

Muthoifin. 2015. Sistem Pendidikan Nasional dan Pendidikan Islam: Studi Kritis Pemikiran Ki Hadjar Dewantara Perspektif Islam, dalam Jurnal Wahana Akademika, Vol. 2, No. 1: 69-72.

Praherdhiono, H., Adi, E. P., Prihatmoko, Y., Nindigraha, N., Soepriyanto, Y., Indreswari, H., \& Oktaviani, H. I. (2020). IMPLEMENTASI PEMBELAJARAN DI ERA DAN PASCA PANDEMI COVID-19. Seribu Bintang.

Pratama, R. A. (2019). Kuliah Melalui Whatsapp (Kulwapp). De Fermat: Jurnal Pendidikan Matematika, 2(1), 17-27.

Purwanto, A., Pramono, R., Asbari, M., Hyun, C. C., Wijayanti, L. M., \& Putri, R. S. (2020). Studi Eksploratif Dampak Pandemi COVID-19 Terhadap Proses Pembelajaran Online di Sekolah Dasar. EduPsyCouns: Journal of Education, Psychology and Counseling, 2(1), 1-12.

Reichenbächer, M., \& Einax, J. W. (2011). Challenges in analytical quality assurance. Springer Science \& Business Media.

Robert W Ewy. (2009):1. Stakeholder Driven Strategic Planning in Education, A Practical Guide for Developing and Deploying Successful Long Range Plans. Wisconsin: ASQ Qualty Press

Rusdiana, A., Sulhan, M., Arifin, I. Z., \& Kamaludin, U. A. (2020). Penerapan Model POE2WE Berbasis Blended Learning Google Classroom Pada Pembelajaran Masa WFH Pandemic Covid-19.

Sallis, Edward. 2002. Total Quality Mamagement in Education. London: Kogen Page.Ltd

Sani Ridwan, Abdullah., Pramuniati, Isda., Mucktiany, Anies. (2015). Penjaminan Mutu Sekolah. Jakarta : Bumi Aksara

Salamah, U. (2018). Penjaminan Mutu Penilaian Pendidikan. EVALUASI: Jurnal Manajemen Pendidikan Islam, 2(1), 274-293.

Shelton, K. (2011). A review of paradigms for evaluating the quality of online education programs. Online Journal of Distance Learning Administration, 4(1), 1-11. 
Sohrabi, C., Alsafi, Z., O’Neill, N., Khan, M., Kerwan, A., Al-Jabir, A., ... \& Agha, R. (2020). World Health Organization declares global emergency: A review of the 2019 novel coronavirus (COVID-19). International Journal of Surgery.

Sugiyono. (2018). Metode Penelitian Kuantitatif, Kualitatif dan REDD. Bandung: Alfabeta.

Sumiati, S., Sasongko, R. N., \& Winarni, E. W. (2013). Manajemen Penjamin Mutu Pada Standar Proses Pendidikan (Studi Deskriptif Kualitatif di SMA Negeri 1 Kepahiang) (Doctoral dissertation, Universitas Bengkulu).

UNESCO. (2020, April 26) . COVID-19 Educational Disruption and Response: COVID-19 Impact on Education. https://en.unesco.org/covid19/educationresponse

Verawardina, U., Asnur, L., Lubis, A. L., Hendriyani, Y., Ramadhani, D., Dewi, I. P., ... \& Sriwahyuni, T. (2020). Reviewing Online Learning Facing the Covid-19 Outbreak. Journal of Talent Development and Excellence, 12(3s), 385-392.

Wilder-Smith, A., \& Freedman, D. O. (2020). Isolation, quarantine, social distancing and community containment: pivotal role for old-style public health measures in the novel coronavirus (2019-nCoV) outbreak. Journal of travel medicine, 27(2), taaa020.

Zain, R., Ahmad, Z. A., \& Suyani, N. (2015). Implementasi, Standar Mutu, dan Penjaminan Mutu E-learning di Perguruan Tinggi. Disampaikan pada Pelatihan Penjaminan Mutu E-learning Universitas Janabadra oleh NCIE (National Consortium for Implementing E-leaning. 